trons, and the de Gennes contributions to the theory. A chapter on (electrostatic) field interaction and its effect on magnetic and thermal behaviour of rare compounds pays tribute to the pioneer work of Penney and Schlapp, Bleaney and Stevens, and Van Vleck which helps us to explain so much of this work. $A$ helpful illustration is given of the use of the Stevens operator equivalent method of dealing with the magnetic and thermal effects of the crystalline ficld on rare earth ions, but it is difficult to understand the necessity or wisdom of including in this book an appendix of forty-eight very closely packed pages of numerical data on energics, eigenfunetions, and so on of rare earth ions in a hexagonal field.

I much appreciated the orderly layout of the five chapters on rare earth-nontransition metal systems, and of the four chapters on rare earth-transition metal systems in which $\mathrm{Ni}, \mathrm{Co}, \mathrm{Fe}$ and $\mathrm{Mn}$ loom large, each with its wealth of tables of magnetic characteristics and graphs of magnetic and thermal behaviour. I was also interested in the many references to the Kondo effect, and to Mössbauer and neutron diffraction experiments. Much discussion is given to phenomena which are associated with the filling of the $d$ bands in the transition metals-the variation of the magnetic moment of cobalt and iron with temperature. A brief treatment is given of the use of rare earth materials for permanent magnets, where the rare earth is thought to provide a uniaxial crystal with high Curie point, large saturation magnetisation and strong anisotropy. The commercial evaluation of the $\mathrm{RCO}_{\mathrm{r}}$ system is in its infancy; the $\mathrm{RFe}$ systems do not scem encouraging, but perhaps $\mathrm{RFeCo}$ systems may later be found to be so.

This is an excellent monograph; though it would be improved by the addition of a subject index.

$$
\text { L. F. Bates }
$$

\section{Inorganic initiation}

Inorganic Chemistry: Principles of Structure and Reactivity. By James E: Huheey. Pp. xvi+737. (Harper and Row: New York, Evanston, San Francisco and London, 1972.) £3.85.

THIS is an interesting, original and stimulating book but a difficult one to place: it certainly cannot be regarded as a comprehensive text on inorganic chemistry. Its main aim scems to be to introduce the university student to the fascination of research publications in many areas of modern inorganic chemistry: it starts typically with perbromate on page 1 and xenon tetroxide on page 2 .

The first two thirds of the book are concerned with the development and application of principles, the emphasis throughout being on structure and bonding in molecular compounds and complexes. Solid state chemistry and thermodynamics are virtually absent, but there is a very full discussion of the many attempts to rationalise covalent bonding in inorganic systems. The last third is a series of essays on such topies as organometallic chemistry; chains, rings and cages; noble-gas and positivehalogen chemistry; lanthanides and actinides; and biological systems.

The book is very easy to read, full of delightful touches, and clearly the work of an enthusiastic teacher. It is well illustrated and has excellent references to further readings on a wide varicty of subjects. It will surely appeal to many students and it is excellent value.

\section{S. G. PHILlitPs}

\section{This earthly life}

Life on Farth. By Edward O. Wilson et al. Pp. xi + 1033. (Sinauer: Stamford, Conn; Freeman: Reading, September 1973.) $£ 5.40$.

THIs college biology textbook claims to "pioncer a new generation" of such publications. If it is not, perhaps, such a complete innovation as this, it is, nevertheless, a good basic book which has some unique features.

A publication which boasts eight authors runs the risk of presenting a divisive view of its subject, but the quintessence of modern biology offered here escapes this hazard. Although the sections differ in style and approach, these differences merely reflect the intrinsic differences in their themes and $a$ sound system of indexing and cross reference helps to unify the whole.

It starts with a kind of prologue, "Life on the Third Planet". 'There" is an opening quotation from James $\mathrm{A}$. Lovell who saw the earth, as he returned to it in Apollo 8, as "the only place that had color, the only place that had life that had warmth... that was home to us". The first of the five main sections, "The" Cell", covers, in about one quarter of the book, the structure of the cell, biological reactions, cnzymes, energy, codes and genes, genetics and the control of cell chemistry: Section 2 , "Multicellular Life", again comprises about one quarter of the whole and includes chapters on: development, reproduction, carbon and nitrogen sourees, gas exchange, transport systems, the internal environment, neurobiology, effectors, behaviour instinct and ithology, and the modification of behaviour. Section 3 describes the diversity of life in a traditional way and Section 4, "The Strategy of Evolution", includes chapters on biogeography, the growth and interaction of populations, ecosyst.cms, social behaviour and human evolution. The last section, "Alternate Futures", presents contrasting optimistic and pessimistic prophecies.

In all, this is a comprehensive, exciting and intellectually challenging book which throws illuminating sidelights on the personalities and work of biologists, on the use of biological matcrials in everyday concerns and on the significance of biological processes for mankind. The format is pleasing, if fragmentary, there are many striking photographs, and explanatory diagrams are well corrclated with the text. Controversial issues are developed in parenthetic, colour-panel insertions so that they do not interrupt the development of the main thesis. A list of related readings from specialised books, articles and research papers is given at the end of each chapter. There is a glossary of biological terms. Life on Earth would certainly be a useful volume in a school or college library and might serve as a basic, if weighty, sixth form or college text.

\section{E. J. Vinnicombe}

\section{Interface chemistry}

An Introduction to the Principles of Surface Chemistry. Edited by R. Aveyard and D. A. Haydon. (Cambridge Chemistry Texts.) Pp. xvi+232. (Cambridge University: London, August 1973.) $£ 5.40$ cloth; $£ 2.40$ paper.

THis book is a must for all surface chemists, but particularly those meeting the subject for the first time, either in formal course work or starting research. I also strongly recommend it for all those teaching the subject as it is one of the clearest and most logical expositions of the physical chemistry of interfaces I have cncountered. It assumes the reader is familar with the basic thermodynamies and statistical mechanies met in most undergraduate courses, and on this foundation builds the subject up to a level where the reader can take the subject further by reading some of the heavier texts or recent review articles referred to in the book. It is refreshing to see a limited number of carefully selected, relevant references referred to in the text, rather than the seemingly endless list, bewildering to the beginner, normally cncountered.

The authors do not exceed the aim set in the book's title. It does not attempt to deal in depth with experimental aspects, or applications, of the subject, thus leaving room (unlike many other text books in the field) to give full derivations of many of the more important equations. In short, this book fills a gap in the literature and is well worth the price.

B. VINCENT 